\title{
EFFECTS OF ROOT EXUDATES AND HUMIC SUBSTANCES ON WEATHERING KINETICS
}

\author{
MICHAEL OCHS ${ }^{1}$, IVANO BRUNNER ${ }^{2}$, WERNER STUMM ${ }^{1}$, \\ and BOŽENA ĆOSOVIĆ 3 \\ ${ }^{1}$ Swiss Federal Institute of Technology Zürich (IGW/EAWAG). \\ 8600 Dübendorf, SWITZERLAND; \\ ${ }^{2}$ Swiss Federal Institute for Forest, Snow, and Landscape Research (WSL). \\ 8903 Birmensdorf, SWITZERLAND; \\ ${ }^{3}$ Ruđđer Bošković Institute, Center for Marine Research, 41001 Zagreb, CROATIA
}

\begin{abstract}
The effect of complex natural organic ligands on the weathering kinetics of aluminum oxide was investigated in laboratory experiments. A peat-derived humic substance and root exudates obtained from ectomycorthizal (Picea abies - Hebeloma crustuliniforme) and non-mycorrhizal Norway Spruce trees; and $\gamma-\mathrm{Al}_{2} \mathrm{O}_{3}$ were used as a model system. The experimental weathering rates are in accordance with a surface-controlled dissolution mechanism. The effect of the humic material on dissolution rates appears to depend on the degree of protonation of the humic (macro)molecules: we observed dissolution-enhancement or -inhibition at $\mathrm{pH} 3$ and 4 , respectively. Ectomycorrhizal exudates proved to be effective weathering agents at $\mathrm{pH} \mathrm{4}$, as opposed to humic material and non-mycorrhizal exudates. Our results suggest that (i) the role of humic materials in mineral weathering and podzolization is different from what is commonly thought, and (ii) mineral weathering rates in the rhizosphere may be higher than in the bulk soil.
\end{abstract}

\section{Introduction}

Weathering reactions in terrestrial and aquatic environments are important for the geochemical behavior of a number of elements. Ultimately, the buffer capacity and supply of major cations of natural systems and their ability to cope with atmospheric acidic input is determined by the rate of weathering (Schnoor and Stumm, 1986). The increased dissolution of Al-bearing minerals in soils is considered to be a major ecological consequence of acidic deposition because of the phytotoxicity and buffering action of dissolved Al-species (Cronan and Goldstein; 1989). In connection with acid deposition and wide-spread forest decline, aluminum was proposed as the major toxicant (Ulrich et al., 1980). Jentschke et al. (1991) demonstrated that $\mathrm{Al}^{3+}$ behaves toxically towards ectomycorrhizae by replacing $\mathrm{Ca}^{2+}$ and $\mathrm{Mg}^{2+}$ in the roots and root cortex, leading to chlorosis and hampering photosynthesis by trees. Al-toxicity thresholds under field conditions are uncertain, however (Foster, 1989). In areas of silicate bedrock, modern increases in soil aluminum leaching due to atmospheric acidic input lead to increased Al-concentrations in surface waters (Cronan and Schofield, 1979; Driscoll et al., 1984) which may be toxic to fish (Baker and Schofield, 1982) and other aquatic organisms.

Weathering kinetics of amorphous Al-(hydr)oxides may be the limiting factor with respect to the short-term neutralization of acidic input via aluminum buffering (Mulder et al., 1987). The dissolution of solid aluminum phases may influence other soil processes by remobilizing ad-

Water, Air, and Soil Pollution 68: 213-229, 1993.

(c) 1993 Kluwer Academic Publishers. Printed in the Netherlands. 
sorbed humic substances and other organic acids, especially in spodic horizons (Raab and Stumm, 1992).

Most important with respect to chemical weathering kinetics are the concentration of protons and organic ligands (Stumm and Wollast, 1990; Schnoor, 1990). Furrer and Stumm (1986) demonstrated that simple organic ligands such as salicylate and citrate enhance the dissolution of $\gamma$ $\mathrm{Al}_{2} \mathrm{O}_{3}$. In the present study, we investigated the effect of humic substances and root exudates (and extracts) on the dissolution kinetics of a model mineral, $\gamma-\mathrm{Al}_{2} \mathrm{O}_{3}$, in an attempt to answer the question whether complex organic ligands typically encountered in forest soils enhance or inhibit the weathering of Al-bearing minerals, such as amorphous (hydr)oxides, silicates, and clay minerals.

\section{Methodology}

\subsection{EXPERIMENTAL}

Dissolution experiments were carried out with suspensions of $2.0 \mathrm{~g} \mathrm{~L}^{-1} \gamma-\mathrm{Al}_{2} \mathrm{O}_{3}$ (Aluminiumoxid $\mathrm{C}$, DEGUSSA AG, Germany; the material is also termed $\delta-\mathrm{Al}_{2} \mathrm{O}_{3}$ ). This material was used as a well-defined model mineral which was also employed in earlier studies carried out in our laboratory (Furrer and Stumm, 1986; Raab and Stumm, 1992). It shows the typical dependence of surface characteristics on $\mathrm{pH}$ and other solution variables which is commonly displayed by Alhydroxides and most silicates. There seems to be a remarkably good agreement between the dissolution rates observed with $\gamma-\mathrm{Al}_{2} \mathrm{O}_{3}$ and other Al-bearing (hydr)oxides and silicates such as feldspars and clay minerals (Wieland et al., 1988; Stumm and Wieland, 1990). The $\gamma-\mathrm{Al}_{2} \mathrm{O}_{3}$ is characterized as a non-porous solid with an average particle size of $20 \mathrm{~nm}$ and a specific BET surface area of $100 \pm 15 \mathrm{~m}^{2} \mathrm{~g}^{-1}$. The material was used without further treatment and stored in stock suspensions. The surface proton concentration as a function of $\left[\mathrm{H}^{+}\right]$was determined previously by continuous and discontinuous (batch) alkalimetric surface titrations.

A commercial humic substance (HM) supplied by Aldrich Chemie (formerly EGA-Chemie), Germany, as Na-humate, and exudates obtained from spruce seedlings with (PAHC) and without (PA) ectomycorrhizae were used as models for naturally occurring ligands. The amount of $\mathrm{HM}$ and exudates adsorbed was determined by measuring the residual ligand concentration in solution with a Dohrman or Shimadzu DOC-Analyzer (HM also spectrophotometrically at 254 and 436 $\mathrm{nm}$ in $\mathrm{pH} 7$ phosphate buffer). HM is obtained from peat (Aldrich Chemie, pers. comm.); some of its characteristics are listed in Table 1 . The relatively high $\mathrm{S}$ content and the $\mathrm{C}$ isotope data suggest Dopplerite, a deposit of humic substances in or below peat bogs (Göttlich, 1990) as the source material. Stock solutions contained $1 \mathrm{~g} \mathrm{HM} \mathrm{L}^{-1}$ and were filtered prior to use through a glass filter whose pore size was reduced to $2 \mu \mathrm{m}$ by pre-washing it with sample ("clogged filter"). The filtration removed about $30 \%$ of the inorganic ash but did not change or fractionate HM as confirmed by UV/VIS-spectra, E4/E6-ratio, and out-of-phase a.c. polarographic capacitypotential scans (Ochs, 1991).

Root exudates were obtained from seedlings of Norway spruce (Picea Abies (L.) Karst.) with and without ectomycorrhizae (Figure 1). The fungal partner of the ectomycorrhizal association was Hebeloma crustuliniforme (Bull. ex St. Amans) Quel. The growing of the seedlings in aseptic culture and the in vitro synthesis of the ectomycorrhizae using the Erlenmeyer flasktechnique with a vermiculite-peat moss mixture as substrate is described by Brunner (1992). 
TABLE 1. Some characteristics of HM (the O content is estimated by difference, the molecular weight represents values as obtained on Sephadex $G 25$ fine columns, the $C$ isotope data (ETH 7081) were obtained by AMS measurements)

\begin{tabular}{|c|c|c|c|c|c|c|c|c|c|c|c|}
\hline \multicolumn{5}{|c|}{$\begin{array}{l}\text { elemental anlysis } \\
(\%, \text { ash-free basis })\end{array}$} & \multicolumn{4}{|c|}{$\begin{array}{c}\text { ash } \\
(\%, \text { total weight })\end{array}$} & \multicolumn{3}{|c|}{ atomic ratio } \\
\hline $\mathrm{C}$ & $\mathrm{H}$ & $\mathrm{N}$ & $S$ & $\mathrm{O}$ & $\mathrm{Na}$ & $\mathrm{Ca}$ & $\mathrm{Fe}$ & total & $\mathrm{H} / \mathrm{C}$ & $\mathrm{O} / \mathrm{C}$ & $\mathrm{N} / \mathrm{C}$ \\
\hline 50.17 & 5.43 & 0.88 & 3.26 & 41 & 8 & 0.65 & 1.56 & 30 & 1.3 & 0.6 & 0.02 \\
\hline \multicolumn{4}{|c|}{ mol. wt. (dalton) } & \multicolumn{3}{|c|}{${ }^{14} \mathrm{C}$-age (y BP) } & \multicolumn{2}{|c|}{$\delta^{13} \mathrm{C}(\% 0)$} & \multicolumn{3}{|c|}{$\mathrm{E} 4 / \mathrm{E} 6$} \\
\hline \multicolumn{4}{|c|}{$\cong 1000-5000$} & \multicolumn{3}{|c|}{40250} & \multicolumn{2}{|c|}{-24.7} & \multicolumn{3}{|c|}{6.3} \\
\hline
\end{tabular}

Exudates were obtained as follows: the seedlings were placed carefully in a plexiglass support (Figure 2) and the roots were rinsed repeatedly with double-distilled water. The support was equipped with a perforated lid and placed in a glass beaker. The beaker was filled with doubledistilled water so that only the roots were immersed (about $200 \mathrm{~mL}$ ), and synthethic air saturated with water was bubbled continuously through the liquid. In this way, the $\mathrm{pH}(5.6)$ as well as the liquid volume were held constant during the experiment ( 2 weeks). The resulting solutions of exudates were taken after one and two weeks and used directly. As discussed in section 3.3.2., the material obtained after two weeks may more appropriately be termed extract. No turbidity or discoloration of the solutions was noticeable unless the experiment lasted about 3 weeks. The experiment was repeated with two completely independent generations of trees and fungi (seedlings grown in aseptic culture were only available for generation II). Henceforth, the various exudates will be denoted as follows:
PAHC; PA
$/ \mathrm{I} ; / \mathrm{II}$
exudates of seedlings with and without ectomycorrhizae
$11 ; / 2$
tree and fungal generation one and two
exudates obtained after the 1st (type-1) and 2nd week (type-2)

All weathering experiments were carried out under approximated steady-state conditions in thermostatted glass titration vessels, at $25^{\circ} \mathrm{C}$ in a constant ionic background $\left(0.1 \mathrm{M} \mathrm{NaNO}_{3}\right)$. When organic ligands were present, the experiments were carried out in the dark. With an automatic titrator (METROHM pH-meter 605, Impulsomat 614, Dosimat 665) that replaced the protons consumed in the dissolution process as $0.1 \mathrm{M} \mathrm{HNO}_{3},\left[\mathrm{H}^{+}\right]$was continuously monitored and kept constant ( $\pm 0.4 \mathrm{mV} \cong 0.01 \mathrm{pH}$-units). Depending on the desired $\mathrm{pH}, 0.5-4 \mathrm{~mL}$ acid were added in total during an experiment performed with $150 \mathrm{~mL}$ suspension. To measure $\left[\mathrm{H}^{+}\right] \mathrm{di}-$ rectly, we used a Ross combination pH-electrode (Orion Research) that was calibrated before and after an experiment by Gran-titrations of the ionic medium at $25^{\circ} \mathrm{C}$. Typical dissolution experiments lasted from 80 to 140 hours.

The dissolution process was determined by monitoring the concentration of dissolved Al in solution. At recorded time intervals, $2-2.5 \mathrm{~mL}$ samples were taken with a syringe and filtered through a $0.01 \mu \mathrm{m}$ cellulose nitrate membrane filter (Sartorius) to separate the solid phase. Al was then determined spectrophotometrically at $585 \mathrm{~nm}$ as Al-pryrocatechol violet complex (Dougan and Wilson, 1974). The advantages of this method are (i) minimum interference from $\gamma$ $\mathrm{Al}_{2} \mathrm{O}_{3}$-particles that could possibly pass through or by the filter, and (ii) no interference from humic substances below $20-50 \mathrm{mg} \mathrm{L}^{-1}$ DOC (Røyset and Sullivan, 1986). It was verified experimentally that filtration did not result in erroneous Al determination. 
TABLE 1. Some characteristics of HM (the $O$ content is estimated by difference, the molecular weight represents values as obtained on Sephadex G 25 fine columns, the C isotope data (ETH 7081) were obtained by AMS measurements)

\begin{tabular}{|c|c|c|c|c|c|c|c|c|c|c|c|}
\hline \multicolumn{4}{|c|}{$\begin{array}{l}\text { elemental anlysis } \\
\text { (\%, ash-free basis) }\end{array}$} & \multicolumn{5}{|c|}{$\begin{array}{c}\text { ash } \\
(\%, \text { total weight })\end{array}$} & \multicolumn{3}{|c|}{ atomic ratio } \\
\hline $\mathrm{C}$ & $\mathrm{H}$ & $\mathrm{N}$ & $\mathrm{S}$ & $\mathrm{O}$ & $\mathrm{Na}$ & $\mathrm{Ca}$ & $\mathrm{Fe}$ & total & $\mathrm{H} / \mathrm{C}$ & $\mathrm{O} / \mathrm{C}$ & $\mathrm{N} / \mathrm{C}$ \\
\hline 50.17 & 5.43 & 0.88 & 3.26 & 41 & 8 & 0.65 & 1.56 & 30 & 1.3 & 0.6 & 0.02 \\
\hline \multicolumn{4}{|c|}{ mol. wt. (dalton) } & \multicolumn{3}{|c|}{${ }^{14} \mathrm{C}$-age (y BP) } & \multicolumn{2}{|c|}{$\delta^{13} \mathrm{C}(\%)$} & \multicolumn{3}{|c|}{ E4/E6 } \\
\hline \multicolumn{4}{|c|}{$\cong 1000-5000$} & \multicolumn{3}{|c|}{40250} & \multicolumn{2}{|c|}{-24.7} & \multicolumn{3}{|c|}{6.3} \\
\hline
\end{tabular}

Exudates were obtained as follows: the seedlings were placed carefully in a plexiglass support (Figure 2) and the roots were rinsed repeatedly with double-distilled water. The support was equipped with a perforated lid and placed in a glass beaker. The beaker was filled with doubledistilled water so that only the roots were immersed (about $200 \mathrm{~mL}$ ), and synthethic air saturated with water was bubbled continuously through the liquid. In this way, the $\mathrm{pH}(5.6)$ as well as the liquid volume were held constant during the experiment ( 2 weeks). The resulting solutions of exudates were taken after one and two weeks and used directly. As discussed in section 3.3.2., the material obtained after two weeks may more appropriately be termed extract. No turbidity or discoloration of the solutions was noticeable unless the experiment lasted about 3 weeks. The experiment was repeated with two completely independent generations of trees and fungi (seedlings grown in aseptic culture were only available for generation II). Henceforth, the various exudates will be denoted as follows:

PAHC; PA exudates of seedlings with and without ectomycorrhizae $/ \mathrm{I} ; / \mathrm{II} \quad$ tree and fungal generation one and two $/ 1 ; / 2 \quad$ exudates obtained after the 1 st (type-1) and 2 nd week (type-2)

All weathering experiments were carried out under approximated steady-state conditions in thermostatted glass titration vessels, at $25^{\circ} \mathrm{C}$ in a constant ionic background $\left(0.1 \mathrm{M} \mathrm{NaNO}_{3}\right)$. When organic ligands were present, the experiments were carried out in the dark. With an automatic titrator (METROHM pH-meter 605, Impulsomat 614, Dosimat 665) that replaced the protons consumed in the dissolution process as $0.1 \mathrm{M} \mathrm{HNO}_{3},\left[\mathrm{H}^{+}\right]$was continuously monitored and kept constant $( \pm 0.4 \mathrm{mV} \cong 0.01 \mathrm{pH}$-units). Depending on the desired $\mathrm{pH}, 0.5-4 \mathrm{~mL}$ acid were added in total during an experiment performed with $150 \mathrm{~mL}$ suspension. To measure $\left[\mathrm{H}^{+}\right] \mathrm{di}-$ rectly, we used a Ross combination pH-electrode (Orion Research) that was calibrated before and after an experiment by Gran-titrations of the ionic medium at $25^{\circ} \mathrm{C}$. Typical dissolution experiments lasted from 80 to 140 hours.

The dissolution process was determined by monitoring the concentration of dissolved $\mathrm{Al}$ in solution. At recorded time intervals, $2-2.5 \mathrm{~mL}$ samples were taken with a syringe and filtered through a $0.01 \mu \mathrm{m}$ cellulose nitrate membrane filter (Sartorius) to separate the solid phase. Al was then determined spectrophotometrically at $585 \mathrm{~nm}$ as Al-pryrocatechol violet complex (Dougan and Wilson, 1974). The advantages of this method are (i) minimum interference from $\gamma$ $\mathrm{Al}_{2} \mathrm{O}_{3}$-particles that could possibly pass through or by the filter, and (ii) no interference from humic substances below $20-50 \mathrm{mg} \mathrm{L}^{-1}$ DOC (Røyset and Sullivan, 1986). It was verified experimentally that filtration did not result in erroneous Al determination. 


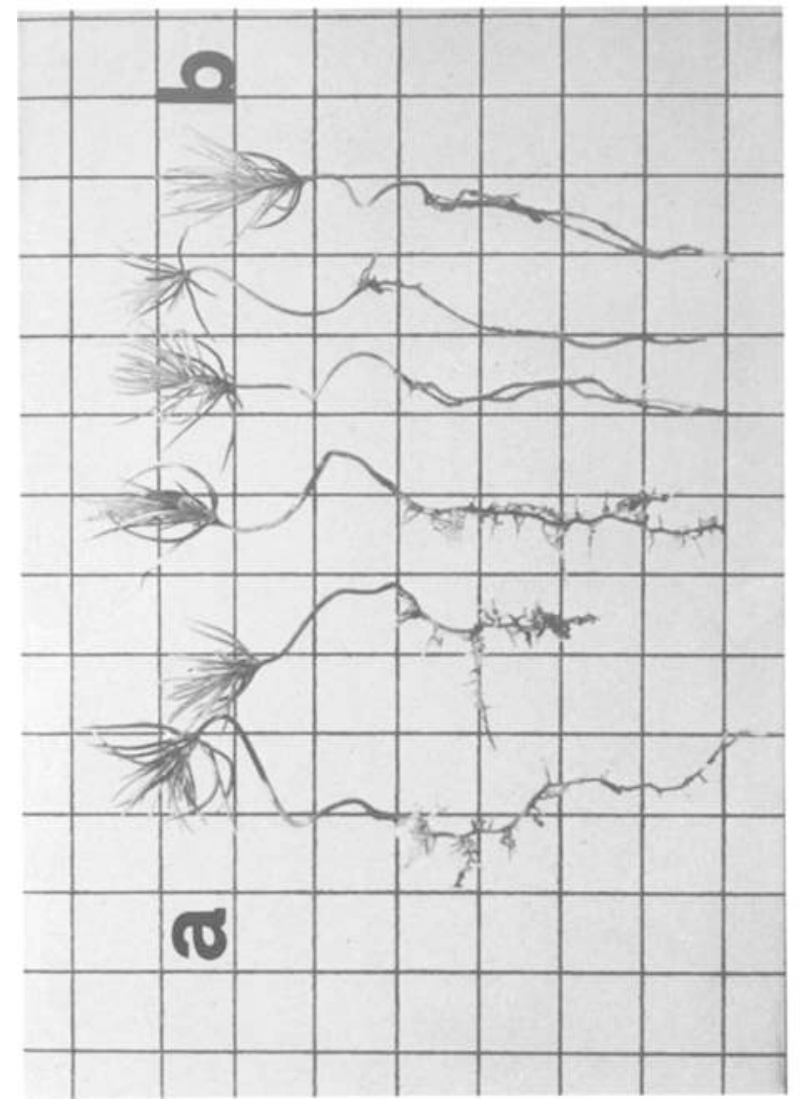

Figure 1. Ectomycorrhizal (a) and non-mycorrhizal (b) seedlings of Picea abies (grid size $=1 \mathrm{~cm}$ ).

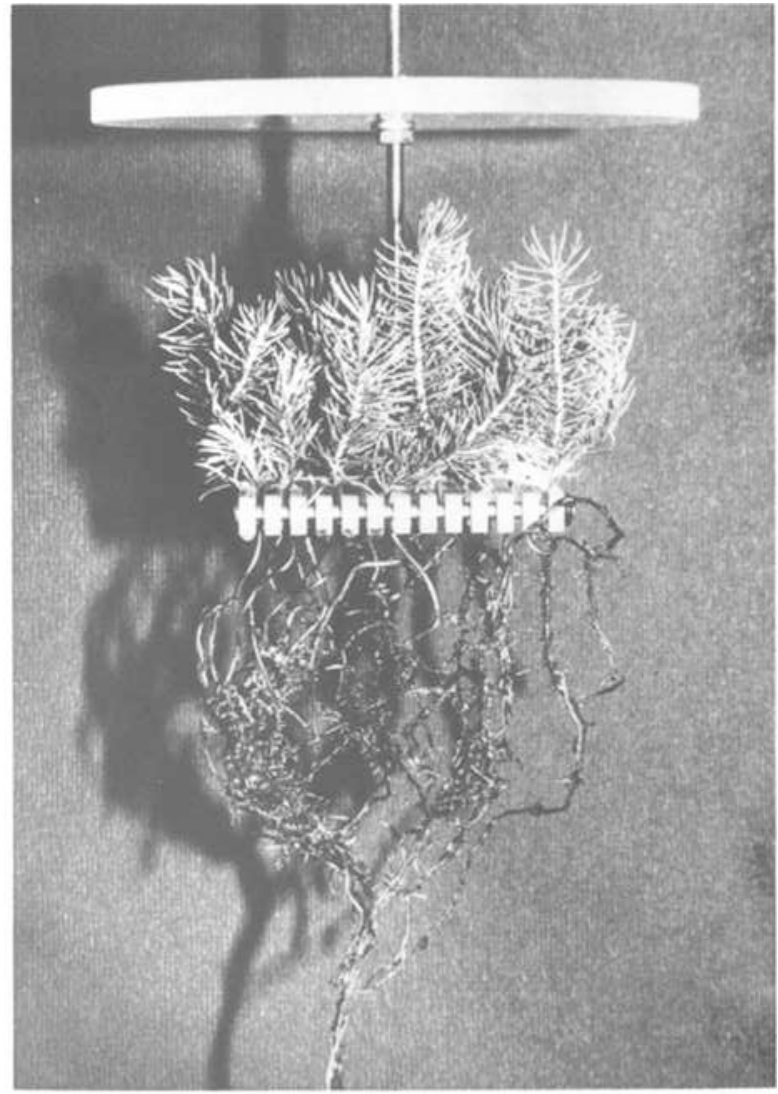

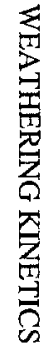

Figure 2. Arrangement of 20 ectomycorrhizal seedlings in a support with screw-on perforated lid. To collect exudates, the support was placed in a glass beaker. 
Overall dissolution rates were calculated from the slopes of regression analyses applied to the linear portion of plots of the original data. Obviously, [Al] at the beginning of the reaction is not exactly the same in all experiments. Thus, in order to facilitate the comparison of all data, the original curves are normalized with respect to their theoretical origin $\left([\mathrm{Al}]^{*}=[\mathrm{Al}]_{\text {time=t }}\right.$ $[\mathrm{Al}]_{\text {time }=0}$; where $[\mathrm{Al}]^{*}$ is the normalized concentration, $[\mathrm{Al}]_{\text {time }=\mathrm{t}}$ refers to the original data points, and $[\mathrm{Al}]_{\mathrm{time}=0}$ refers to the $\mathrm{y}$-intercept of the corresponding regression line).

\subsection{CHEMICAL WEATHERING KINETICS}

To date, a variety of theoretical and practical approaches for the description of weathering phenomena can be found in the literature. Most commonly, weathering was treated in terms of (quasi-) equilibrium models, whereas the application of chemical kinetics to weathering reactions is a comparatively recent development. Of the steps occurring in a weathering reaction - (1) transport of dissolved weathering agents from the bulk solution to the mineral surface, (2) adsorption of the solutes, (3) reactions at the surface, (4) detachment of reactants, and (5) transport of reactants to the bulk solution - step (4) is in many cases the slowest and is therefore ratelimiting (Stumm and Wollast, 1990). The dissolution process of readily soluble salts and carbonates deviates from this rule.

From a chemical perspective, the dissolution of a mineral can be described as a change of the coordinative environment of the mineral's central metal ions. This may be exemplified by the following reaction scheme (Valverde and Wagner, 1976):

$$
\begin{aligned}
& \mathrm{M}^{\mathrm{n}+}(\text { mineral })+\mathrm{H}_{2} \mathrm{O}=\mathrm{M}^{\mathrm{n}+}(\mathrm{aq}) \\
& \mathrm{M}^{\mathrm{n}+}(\text { mineral })+\mathrm{L}^{\mathrm{m}-}+\mathrm{H}_{2} \mathrm{O}=\mathrm{ML}^{\mathrm{n}-\mathrm{m}}(\mathrm{aq}) \\
& \mathrm{O}^{2-}+2 \mathrm{H}^{+}(\mathrm{aq})=\mathrm{H}_{2} \mathrm{O}
\end{aligned}
$$

Here, the metal center $\left(\mathrm{M}^{\mathrm{n}+}\right)$ in the crystal lattice of the mineral exchanges its $\mathrm{O}^{2-}$ ligands for some other ligands. The most important ligands responsible for mineral weathering are $\mathrm{H}_{2} \mathrm{O}, \mathrm{H}^{+}$, and $\mathrm{OH}^{-}$, and (mostly organic) complex-formers.

Typically, empirical rate laws are formulated as follows:

$$
\begin{aligned}
& \mathbf{R}_{\mathrm{H}}=\mathrm{k}_{\mathrm{H}}\left[\mathrm{H}^{+}\right]^{\mathrm{n}} \\
& \mathrm{R}_{\mathrm{L}}=\mathrm{k}_{\mathrm{L}}\left[\mathrm{L}^{-}\right]^{\mathrm{m}}
\end{aligned}
$$

where $\mathrm{R}$ is the experimentally determined rate, $\mathrm{k}$ is the kinetic rate constant, and $\mathrm{n}$ and $\mathrm{m}$ are empirical fractional exponents. The subscripts " $H$ " and " $L$ " refer to proton- and ligand-promoted dissolution, respectively. Based on the surface complexation model (Schindler et al., 1976; Stumm et al., 1976), Furrer and Stumm (1986) propose that surface complexes of any ligand should be treated as chemical species and enter directly into dissolution rate laws:

$$
\mathrm{R}_{\mathrm{H}}=\mathrm{k}_{\mathrm{H}}\left\{>\mathrm{MOH}_{2}{ }^{+}\right\}^{\mathrm{n}}=\mathrm{k}_{\mathrm{H}}\left(\mathrm{c}_{\mathrm{H}}^{\mathrm{s}}\right)^{\mathrm{n}}
$$

where $\left\{>\mathrm{MOH}_{2}{ }^{+}\right\}$is the concentration of protonated surface hydroxo groups, and $\mathrm{c}_{\mathrm{H}}^{\mathrm{s}}$ is the surface concentration of adsorbed protons. We can treat ligand-promoted dissolution in a similar way and obtain:

$$
\mathrm{R}_{\mathrm{L}}=\mathbf{k}_{\mathrm{L}}\{>\mathrm{ML}\}
$$


We can assume that protons and ligands do not compete with each other in the dissolution reaction. Different organic ligands, however, are likely to compete for the same surface sites. The overall dissolution rate $\mathrm{R}_{\text {tot }}$ may thus be composed of several individual rates (Furrer and Stum$\mathrm{m}, 1986)$ :

$$
\mathrm{R}_{\mathrm{tot}}=\mathrm{R}_{\mathrm{H}}+\mathrm{R}_{\mathrm{L}, 1}+\mathrm{R}_{\mathrm{L}, 2}+\cdots
$$

The principles outlined above can be applied to describe the weathering kinetics of clays, silicates, and whole soil horizons (Stumm and Wollast, 1990; Schnoor, 1990; Asolekar et al., 1991).

\section{Results and Discussion}

\subsection{THE PROTON-PROMOTED DISSOLUTION}

In laboratory weathering experiments, the experimentally accessible quantity is the overall dissolution rate $\mathrm{R}_{\text {tot }}$. In order to determine the contribution of adsorbed organic ligands to the overall weathering reaction, the proton-promoted dissolution rate $R_{H}$ (i.e. the rate of dissolution caused by water at a certain $\mathrm{pH}$ ) must be measured first and $R_{\mathrm{L}}$ can then be calculated as $R_{\text {tot }}-R_{H}$. Thus, the knowledge of $\mathrm{R}_{\mathrm{H}}$ at different solution $\mathrm{pH}$-values allows (i) an evaluation of the effect of a particular ligand as a function of $\mathrm{pH}$, and (ii) a comparison of the effectiveness of different ligands under standardized conditions.

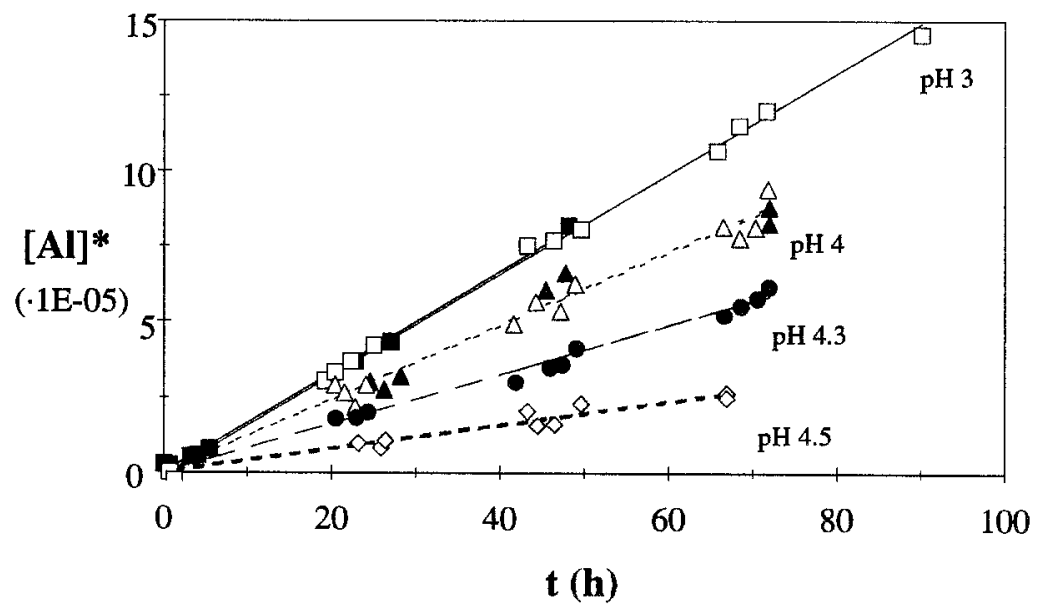

Figure 3. The proton-promoted dissolution of $\gamma-\mathrm{Al}_{2} \mathrm{O}_{3}$. Note that [Al]* refers to the normalized concentration of $\mathrm{Al}$.

The dissolution process of $\gamma-\mathrm{Al}_{2} \mathrm{O}_{3}$ at $\mathrm{pH}$-values between 3 and 4.5 is illustrated in Figure 3 . This graph shows that linear dissolution rates were obtained after $20 \mathrm{~h}$ at all pH-values investigated, and that the reproducibility of individual dissolution experiments at $\mathrm{pH} 3$ and 4 was excellent. The slopes of the regression lines (conditional rates) and the corresponding values of $R_{H}$ 
(specific rates) are listed in Table 2. $\mathrm{R}_{\mathrm{H}}$ was derived from the conditional dissolution rates using the BET surface area of $\gamma-\mathrm{Al}_{2} \mathrm{O}_{3}$.

$\mathrm{R}_{\mathrm{H}}$ is not a linear function of the solution $\mathrm{pH}$ but of the concentration of protons adsorbed at the surface $c_{\mathrm{H}}^{\mathrm{s}}$ (Furrer and Stumm, 1986). The rate of the proton-promoted dissolution of $\gamma-\mathrm{Al}_{2} \mathrm{O}_{3}$ can thus be expressed as

$$
\mathrm{RH}=\mathrm{k}_{\mathrm{H}}\left(\mathrm{c}_{\mathrm{H}}^{\mathrm{s}}\right)^{3.2}
$$

where the rate constant $\mathrm{k}_{\mathrm{H}}=1.74 \cdot 10^{10}\left(\mathrm{~mol}^{-2} \mathrm{~m}^{4} \mathrm{~h}^{-1}\right)$. This value agrees within $1 / 2$ order of magnitude with the value found by Furrer and Stumm (1986).

TABLE 2. Values for the proton-promoted dissolution. The conditional rate is equal to the slopes of the regression lines in Figure 3 and refers to $2 \mathrm{~g} \mathrm{~L}^{-1} \gamma-\mathrm{Al}_{2} \mathrm{O}_{3}$.

\begin{tabular}{cccc}
\hline $\mathrm{pH}$ & $\begin{array}{c}\text { conditional rate } \\
\left(\mathrm{umol} \mathrm{Al} \mathrm{h}^{-1}\right)\end{array}$ & $\begin{array}{c}\mathrm{R}_{\mathrm{tot}}=\mathrm{R}_{\mathbf{H}} \\
\left(\mathrm{nmol} \mathrm{Al} \mathrm{h}^{-1} \mathrm{~m}^{-2}\right)\end{array}$ & $\mathrm{r}^{2}$ \\
\hline 3 & 1.66 & 8.30 & 0.99 \\
3 & 1.67 & 8.35 & 0.99 \\
4 & 1.22 & 6.11 & 0.97 \\
4 & 1.21 & 6.05 & 0.97 \\
4.3 & 0.82 & 4.09 & 0.98 \\
4.5 & 0.39 & 1.96 & 0.89 \\
\hline
\end{tabular}

\subsection{THE CONTRASTING EFFECTS OF HM ON WEATHERING RATES}

Figure 4. illustrates the dissolution process of $\gamma-\mathrm{Al}_{2} \mathrm{O}_{3}$ in the presence of $\mathrm{HM}$ at $\mathrm{pH} 3$ and 4. The total and ligand-promoted dissolution rates are listed in Table 3. From Figure 4. one can note immediately the apparent inhibition of the dissolution reaction by $\mathrm{HM}$ at $\mathrm{pH} 4$. An inhibition of dissolution reactions by polyvalent or hydrophobic organic ligands has been considered possible (Rubio and Matijevic, 1979; Stumm and Wollast, 1990), but to date there are very few experimental studies to substantiate this hypothesis. As a matter of fact, by far the most studies concerning the influence of humic substances on weathering kinetics reported a significant enhancement of mineral dissolution in the presence of humic or fulvic acids (Huang and Keller, 1972; Kodama et al., 1983; Tan, 1980, 1986). Since in most studies the solution pH was not strictly controlled, humic substances may have lead to an enhancement of mineral dissolution simply by lowering the $\mathrm{pH}$ and not by acting as complex formers (inhibition of mineral dissolution by adsorbed humic material could theoretically be overcome by a decrease in solution $\mathrm{pH}$ caused by non-adsorbed humic material, resulting in a net increase in dissolution). However, one must focus on the complexing action of humic matter since (i) humic substances are much stronger ligands than acids, and (ii) even acidic soils are comparatively well buffered and the $\mathrm{pH}$ is controlled by factors other than humic material (as it was in the present study). Only recently, Chin and Mills (1991) reported that humic substances had either no effect or an inhibitory effect on the dissolution of kaolinite in well-controlled experiments, but did not observe linear dissolution processes.

The inhibition of dissolution can be interpreted as a blocking of surface sites by adsorbed HM-molecules that effectively prevents the detachment of the metal centers. As shown by Furrer 
and Stumm (1986), monodentate surface complexes (e.g. with benzoate) have little effect on the dissolution rate, whereas bidentate (mononuclear) surface complexes (e.g. with oxalate or salicylate) lead to a significant enhancement of dissolution processes by forming an activated complex with one of the surface metal centers.

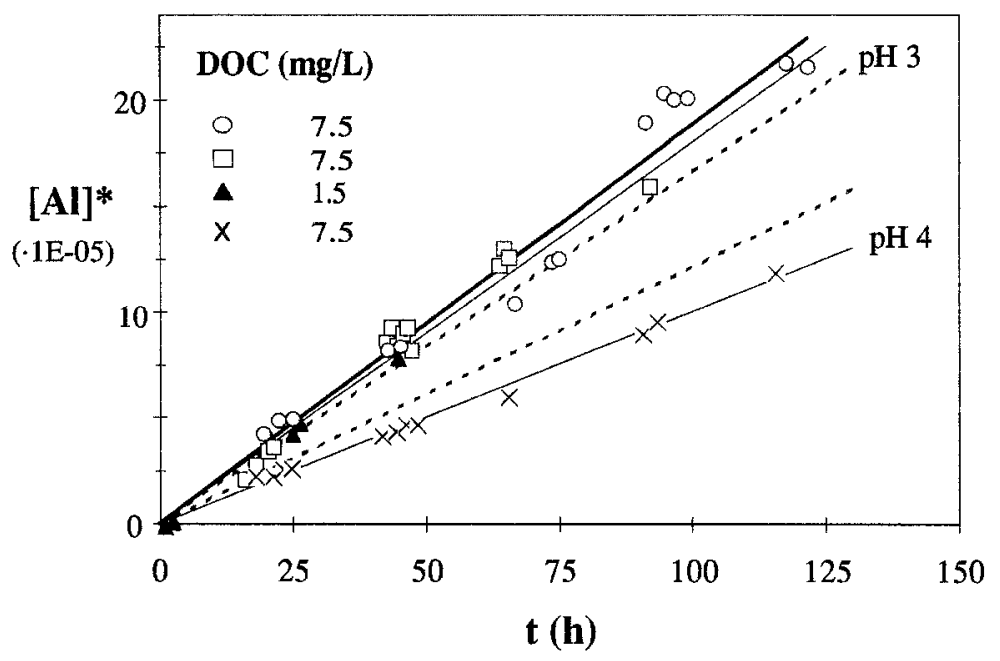

Figure 4. The dissolution of $\gamma-\mathrm{Al}_{2} \mathrm{O}_{3}$ in the presence of HM. The solid lines were obtained through regression analysis of the experimental data, the dashed lines represent $R_{H}$ at $\mathrm{pH} 3$ and 4 (see Figure 3.).

TABLE 3. Values for $R_{\text {tot }}$ and $R_{H M}$ as obtained from Figure 4. The respective values for $R_{H}$ are listed in Table 2 .

\begin{tabular}{ccccc}
\hline $\mathrm{pH}$ & $\begin{array}{c}\mathrm{c}_{\mathrm{HM}} \\
\left(\mathrm{mg} \mathrm{DOC} \mathrm{L}^{-1}\right)\end{array}$ & $\begin{array}{c}\mathrm{R}_{\text {tot }} \\
\left(\mathrm{nmol} \mathrm{Al} \mathrm{h}^{-1} \mathrm{~m}^{-2}\right)\end{array}$ & $\begin{array}{c}\mathrm{R}_{\mathrm{HM}} \\
\left(\mathrm{nmol} \mathrm{Al} \mathrm{h}^{-1} \mathrm{~m}^{-2}\right)\end{array}$ & $\mathrm{r}^{2}$ \\
\hline 3 & 1.5 & 9.00 & 0.68 & 0.99 \\
3 & 7.5 & 9.35 & 1.03 & 0.98 \\
3 & 7.5 & 9.47 & 1.15 & 0.96 \\
4 & 7.5 & 5.02 & -1.06 & 0.99 \\
\hline
\end{tabular}

Consequently, bi- or polynuclear surface complexes could hamper the detachment through bridging several surface metal centers. Thus, the simultaneous breaking of several metal- $\mathrm{O}^{2-}$ bonds would be required for a detachment, making the process more unlikely with an increasing number of complexed surface metal centers. These surface complexes are illustrated schematically in Figure 5. The contrasting behavior of $\mathrm{HM}$ at $\mathrm{pH} 3$ and 4 is consistent with this explanation: the lower the $\mathrm{pH}$, the more functional groups on a humic molecule will be protonated and thus be unavailable for the formation of coordinative bonds with the metal centers at the mineral surface. Thus, the formation of bi- or polynuclear complexes is more likely at $\mathrm{pH} 4$ than at $\mathrm{pH} 3$. 
One could also hypothesize (Stumm and Wollast, 1990) that HM blocks some surface sites by hydrophobic adsorbtion. But a comparison of the adsorption behavior of $\mathrm{HM}$ at the hydrophilic, polar $\gamma$ - $\mathrm{Al}_{2} \mathrm{O}_{3}$-surface and the hydrophobic, non-polar uncharged mercury electrode (Ochs, 1991) showed that (i) ligand-exchange reactions are mainly responsible for the adsorption at the $\gamma$ $\mathrm{Al}_{2} \mathrm{O}_{3}$-surface, and (ii) no significant difference in the hydrophobicity of $\mathrm{HM}$ can be expected between pH 3 and 4. Further, it is known that a blocking of surface sites may result from the coordinative adsorption of metal cations (cf. Stumm and Wollast, 1990). In the case of HM, Fe is the only metal of interest, and $[\mathrm{Fe}]_{\text {tot }}$ - most of which we can assume to be bound to HM - ranged from less than $1 \mathrm{nM}$ to $4.2 \mathrm{nM}$ during dissolution experiments. Thus, this possibility can be safely discarded.
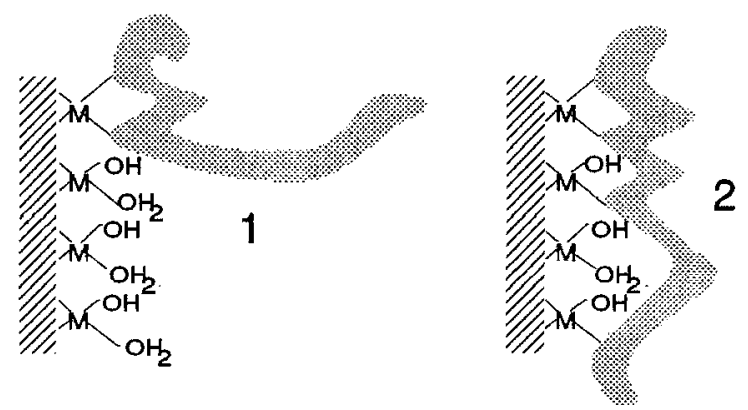

Figure 5. A schematic representation of a humic acid molecule forming mononuclear bidentate (1) and polynuclear (2) surface complexes on a metal oxide surface

For the dissolution of $\gamma-\mathrm{Al}_{2} \mathrm{O}_{3}$ in the presence of $\mathrm{HM}$, it is not possible to formulate a general rate law analogous to Equation (4) because the exact surface speciation of $H M$ is not known. However, we may extract useful apparent rate constants from the data. Since $R_{L}$ is a linear function of a certain surface species (Equation (4)), we may formulate a rate law as follows:

$$
\mathbf{R}_{\mathrm{HM}, \mathrm{pH}}=\mathrm{k}_{\mathrm{HM}, \mathrm{pH}}^{\mathrm{app}} \mathrm{c}_{\mathrm{HM}}
$$

where the subscript " $\mathrm{pH}$ " indicates that the kinetic parameters in this equation are valid only for a specified $\mathrm{pH}$. The apparent rate constant $\mathrm{k}_{\mathrm{HM}, \mathrm{pH}}^{\mathrm{app}}$ implicitly contains information about the surface speciation of $\mathrm{HM}$ and can be obtained as $\mathrm{R}_{\mathrm{HM}, \mathrm{pH}} / \mathrm{c}_{\mathrm{HM}}$. Under the present experimental conditions, $\mathrm{HM}$ is completely adsorbed (>95\%) and can be expected to form a monolayer on the $\gamma-\mathrm{Al}_{2} \mathrm{O}_{3}$ surface (Ochs, 1991). Thus, we may replace $c_{\mathrm{HM}}$ with $\mathrm{c}_{\mathrm{HM}}^{\mathrm{s}}$. The apparent rate constants calculated in this way are listed in Table 4. Published rate constants for simple aliphatic and aromatic acids are included for comparison.

TABLE 4. Apparent rate constants $\mathrm{k}_{\mathrm{L}, \mathrm{pH}}^{\mathrm{app}}\left(\mathrm{h}^{-1}\right)$ for the ligand-promoted dissolution of $\gamma-\mathrm{Al}_{2} \mathrm{O}_{3}\left(0.1 \mathrm{M} \mathrm{NaNO}_{3}, 25^{\circ} \mathrm{C}\right)$. Values for $\mathrm{HM}$ are calculated using an average molecular weight of $3500 \mathrm{~g}$. All other data are calculated from Furrer and Stumm (1986).

\begin{tabular}{cccccc}
\hline $\mathrm{pH}$ & $\mathrm{HM}$ & oxalate & citrate & salicylate & phthalate \\
\hline 3.0 & $3.1 \cdot 10^{-2}$ & $1.1 \cdot 10^{-2}$ & $1.0 \cdot 10^{-3}$ & $6.6 \cdot 10^{-3}$ & $7.5 \cdot 10^{-5}$ \\
4.0 & $-2.9 \cdot 10^{-2}$ & $1.1 \cdot 10^{-2}$ & $2.2 \cdot 10^{-3}$ & $1.0 \cdot 10^{-2}$ & $3.0 \cdot 10^{-3}$ \\
\hline
\end{tabular}


All acids considered in Table 4. except oxalate have apparent rate constants that depend on the $\mathrm{pH}$. The rate constants obtained for citric, salicylic, and phthalic acid are larger at $\mathrm{pH} 4$ than at $\mathrm{pH}$ 3. This is explained by the fact that with increasing $\left[\mathrm{H}^{+}\right]$more and more of the surface complexes become protonated, thus changing from bi- to monodentate coordination. Only the bidentate surface complexes will notably promote the dissolution reaction. Similarly, adsorbed polydentate ligands such as humic substances could be expected to form preferentially mononuclear complexes with increasing, and bi- or polynuclear complexes with decreasing proton concentration.

3.3. MINERAL DISSOLUTION IN THE RHEOSPHERE: A LABORATORY-ABSTRACTION OF AN INTRICATE ENVIRONMENT

3.3.1.Yield and Characteristics of Root Exudates. The DOC-concentration after one or two weeks of bathing the roots in water varied from 3.9 to $6.7 \mathrm{mg} \mathrm{L}^{-1}$. This corresponds to a release of 3.7-6.0 $\mathrm{g}$ organic $\mathrm{C}$ per seedling and day. In this respect, seedlings with and without ectomycorrhizae did not differ significantly. Since only a limited amount of exudates was available, no detailed chemical analysis could be performed as yet.
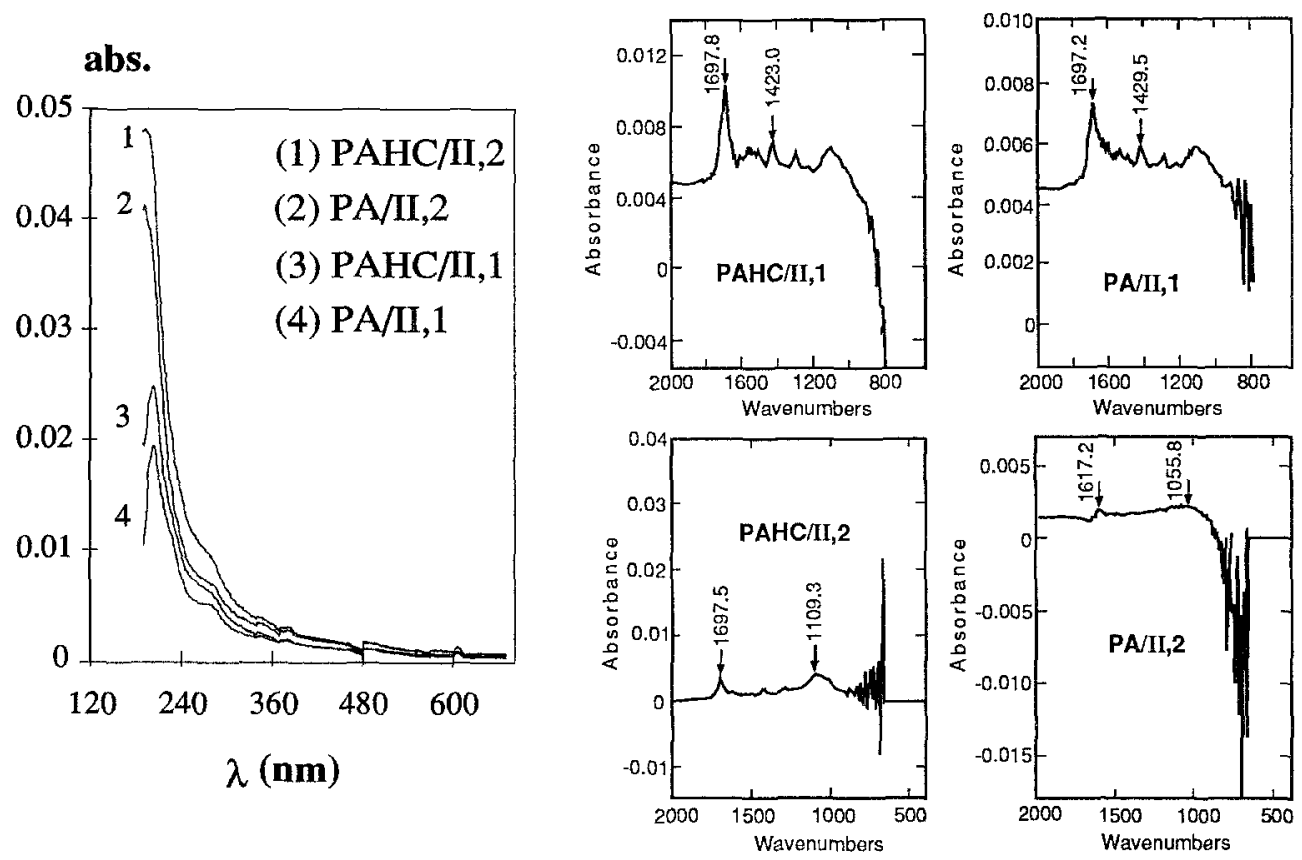

Figure 6. UV/VIS-spectra (left; $\mathrm{pH}=5.6, \mathrm{DOC}=1 \mathrm{mg} \mathrm{L}^{-1}$, cell length $1 \mathrm{~cm}$ ) and ATR-FTIRspectra (right; $\mathrm{pH}=5.6, \mathrm{DOC}=3 \mathrm{mg} \mathrm{L}^{-1}$ ) of solutions of exudates and extracts.

FTIR- and UV/VIS-spectra were directly recorded with small amounts of exudate solution (Figure 6.). The results of a survey of the metal concentration in some exudates by ICP-AES are given in Table 5. Apparently, the seedlings without mycorrhizae released more $\mathrm{K}, \mathrm{Mg}$, and $\mathrm{Ca}$ together with the DOC than the seedlings infected with the fungus. The UV/VIS- and FTIR- 
spectra of PA and PAHC are very similar both for exudates obtained after one and after two weeks. Contrary to that, both types of spectra change drastically from week 1 to week 2 . The most likely explanation is that type- 1 exudates reflect active exudation, whereas type- 2 exudates reflect conditions where lysis may occur and material may be leached from cells. One can safely assume that type- 1 exudates are much more representative for natural conditions than type- 2 exudates/extracts.

TABLE 5. The metal concentration of two types of exudates obtained after one week (determined by ICP-AES, all other metals were at or below the detection limit).

\begin{tabular}{|c|c|c|c|}
\hline $\begin{array}{c}\text { Concentration } \\
\left(\mu \mathrm{mol} \mathrm{mg^{-1 }} \text { DOC) }\right.\end{array}$ & $\mathbf{K}$ & $\mathrm{Mg}$ & $\mathrm{Ca}$ \\
\hline PA & 9.2 & 8.6 & 15 \\
\hline PAHC & 9.7 & 3.3 & 9.9 \\
\hline
\end{tabular}

3.3.2.The Importance of Ectomycorrhizal Exudates in Weathering Reactions. The dissolution of $\gamma-\mathrm{Al}_{2} \mathrm{O}_{3}$ in the presence of organic ligands exuded from tree (Picea abies) roots (PA/1) and ectomycorrhizal associations with Hebeloma crustuliniforme (PAHC/1) is exemplified in Figure 7. The dissolution rates obtained from the slopes of the regression lines are listed in Table 6.

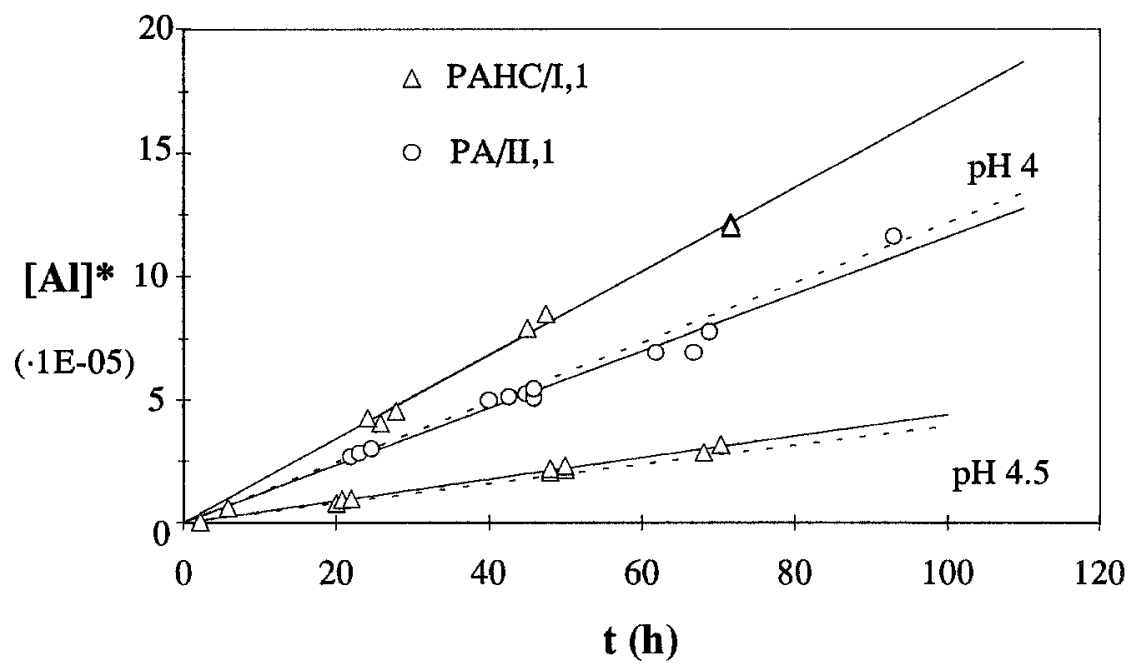

Figure 7. Examples of the dissolution of $\gamma-\mathrm{Al}_{2} \mathrm{O}_{3}$ in the presence of exudates obtained after one week (type-1) from tree roots alone and from ectomycorrhizal roots. The concentration of the exudates was the same in all experiments $\left(3 \mathrm{mg} \mathrm{DOC}^{-1}\right)$. Solid lines are the results of regression analyses, dashed lines refer to $\mathrm{R}_{\mathrm{H}}$ at the respective $\mathrm{pH}$.

The reproducibility of the weathering rate of $\gamma-\mathrm{Al}_{2} \mathrm{O}_{3}$ in the presence of exudates obtained from different generations of plants (/I vs. /II) is remarkable, considering the complexity of, and comparatively little knowledge about mycorrhizal associations. Completely independent genera- 
tions of trees and fungi apparently exude very similar, possibly identical, mixtures of organic ligands under the given experimental conditions.

The most striking result of the experiments with root exudates is the significant effect on the dissolution rate of $\gamma-\mathrm{Al}_{2} \mathrm{O}_{3}$ obtained with the ectomycorrhizal exudates (PAHC) compared with the exudates of the tree roots (PA) alone. Apparent rate constants for the dissolution of $\gamma-\mathrm{Al}_{2} \mathrm{O}_{3}$ in the presence of root exudates are compared with published values for simple organic ligands in Table 7. Because the molecular weights of PAHC and PA are not known, the constants have to be expressed in terms of $\mathrm{mg}$ DOC adsorbed per surface area which slightly distorts the results in comparison with molar units. It becomes clear, however, that PAHC has a strong accelerating effect on the dissolution process at $\mathrm{pH} \mathrm{4}$. On a mg DOC-basis, PAHC seems to be a more effective promoter of weathering reactions than most simple organic acids, except oxalate. At pH 4.5, the effect of PAHC is less pronounced. This is surprising, since the accelerating effect of organic acids usually increases with increasing solution $\mathrm{pH}$. However, PAHC represents a mixture of different substances and the composition of the adsorbed material may thus be different at different pH-values.

TABLE 6. Values for $R_{\text {tot }}$ and $R_{L}$ in the presence of exudates obtained after the first week (type-1).

\begin{tabular}{ccccc}
\hline $\mathrm{pH}$ & $\begin{array}{c}\text { exudate } \\
\left(3 \mathrm{mg} \mathrm{DOC} \mathrm{L}^{-1}\right)\end{array}$ & $\begin{array}{c}\mathrm{R}_{\text {tot }} \\
\left(\mathrm{nmol} \mathrm{Al} \mathrm{h}^{-1} \mathrm{~m}^{-2}\right)\end{array}$ & $\begin{array}{c}\mathrm{R}_{\mathrm{L}} \\
\left(\mathrm{nmol} \mathrm{Al} \mathrm{h}^{-1} \mathrm{~m}^{-2}\right)\end{array}$ & $\mathrm{r}^{2}$ \\
\hline 4 & PAHC/I,1 & 8.48 & 2.41 & 0.99 \\
4 & PAHC/II,1 & 8.63 & 2.55 & 0.95 \\
4.5 & PAHC/I,1 & 2.19 & 0.23 & 0.99 \\
4 & PA/II,1 & 5.78 & -0.29 & 0.97 \\
\hline
\end{tabular}

PA-solutions appear to have an influence on the weathering reaction similar to that of HM. Most likely, the inhibition is caused by the same mechanism as with HM (i.e., bi- or polynuclear surface complexes). Tables 6. and 8. show that solutions of PA (type 1- as well as type 2-exudates) always lead to a significantly slower dissolution reaction than the respective PAHC samples.

Although corresponding samples of PAHC and PA result in drastically different dissolution rates of $\gamma-\mathrm{Al}_{2} \mathrm{O}_{3}$, their FTIR and UV/VIS spectra are practically indistinguishable. Thus, it seems that a rather small fraction of the substances exuded by the mycorrhizae is responsible for the enhancement of $\gamma-\mathrm{Al}_{2} \mathrm{O}_{3}$-dissolution. In combination with known facts about the behavior of various organisms under stress (Winkelmann et al.,1987), this leads to the following possible explanation. It was shown by several authors (Szaniszlo et al., 1981; Akers, 1983) that fungi, including ectomycorhizal fungi, are able to produce certain organic compounds, especially hydroxamic acids, that are very effective in chelating $\mathrm{Fe}^{3+}$ (siderophores). Siderophore production is enhanced by Fe-deficiency. Because of the similarity of $\mathrm{Fe}^{3+}$ and $\mathrm{Al}^{3+}$, it seems very probable that these ligands would also effectively complex Al-centers at a mineral surface, thus forming precursor complexes well suited for the detachment of an Al-organic species.

A comparison of Tables 6 . and 8. shows a marked difference between exudates obtained after the 1st (type 1) and 2nd week (type 2). Both PA and PAHC type-2 exudates lead to a significant decrease of the dissolution rate compared with PA and PAHC type 1-exudates. This difference is 
also reflected in their respective FTIR- and UV/VIS-spectra (Figure 6.) Clearly, these techniques do not allow a detailed anlysis of complex samples, but give valuable "fingerprints". It is also important to note that all type-2 exudates inhibit the dissolution reaction with respect to $R_{H}$. Possibly, this is caused by compounds of relatively high molecular weight leached from the roots after the two-week exposure to water.


the respective ligands $\left(\mathrm{k}_{\mathrm{L}, \mathrm{pH}}^{\text {app DOC }}\right)$. For PAHC, the average values obtained with the exudates of generation I and II are reported. The constants for oxalate, citrate, salicylate, and phthalate are calculated from data of Furrer and Stumm (1986).

\begin{tabular}{ccc}
\hline $\mathrm{pH}$ & ligand & $\mathrm{k}_{\mathrm{L}, \mathrm{pH}}^{\text {app,DOC }}\left(\frac{\mathrm{nmol} \mathrm{Al} \mathrm{h}}{\mathrm{mg} \mathrm{DOC}}\right)$ \\
\hline 4 & $\mathrm{HM}$ & -28.0 \\
4 & PAHC/(I,II $), 1$ & 156.3 \\
4 & $\mathrm{PA} / 1$ & -19.3 \\
4 & oxalate & 419.2 \\
4 & citrate & 30.2 \\
4 & salicylate & 108.6 \\
4 & phthalate & 21.7 \\
\hline 4.5 & PAHC/I,1 & 16.7 \\
4.5 & oxalate & 419.2 \\
4.5 & phthalate & 31.7 \\
\hline
\end{tabular}

TABLE 8. Values for $R_{\text {tot }}$ and $R_{L}$ in the presence of exudates obtained after the second week (type 2)

\begin{tabular}{ccccc}
\hline $\mathrm{pH}$ & $\begin{array}{c}\text { exudate } \\
\left(3 \mathrm{mg} \mathrm{DOC} \mathrm{L}^{-1}\right)\end{array}$ & $\begin{array}{c}\mathbf{R}_{\text {tot }} \\
\left(\mathrm{nmol} \mathrm{Al} \mathrm{h}^{-1} \mathrm{~m}^{-2}\right)\end{array}$ & $\begin{array}{c}\mathbf{R}_{\mathrm{L}} \\
\left(\mathrm{nmol} \mathrm{Al} \mathrm{h}^{-1} \mathrm{~m}^{-2}\right)\end{array}$ & $\mathbf{r}^{2}$ \\
\hline 4 & PAHC/I,2 & 5.23 & -0.85 & 0.89 \\
4 & PAHC/II,2 & 5.17 & -0.94 & 0.99 \\
4 & PA/II,2 & 3.55 & -2.25 & 0.98 \\
\hline
\end{tabular}

\section{Conclusions and Implications}

The longstanding generalization that medium- to high-molecular weight natural organic ligands, such as humic substances, enhance the weathering of minerals (cf. McKeague et al., 1986) seems to be no longer warranted considering the present kinetic data. It became evident that humic substances (and exudates from non-mycorrhizal tree roots) may inhibit the dissolution of minerals even under acidic conditions. Thus, complex polyfunctional and polydisperse substances may behave very differently from simple and defined organic acids with respect to mineral weathering. It may become necessary to reevaluate the role of humic matter in pedogenesis, particularly mineral weathering and podzsolization processes. 
On the other hand, we showed that exudates of ectomycorrhizal trees caused a significant increase of $\gamma-\mathrm{Al}_{2} \mathrm{O}_{3}$-dissolution, suggesting that weathering rates in the rhizosphere may be significantly higher than in the bulk soil. Using a more macroscopic approach, Leyval and Berthelin (1991) observed increased weathering of phlogopite in pine rhizospheres but not in a nonrhizospheric soil. This could have important consequences for the nutrient supply of trees (Boyle and Voigt, 1973; Godo and Reisenauer, 1980; Song and Huang, 1988) and acid neutralizing capacity, as well as the release and complexation of Al in the root zone. Kreuzer et al. (1989) point out that bulk soil $\mathrm{Ca} / \mathrm{Al}$ - and $\mathrm{Mg} / \mathrm{Al}$-ratios are insufficient as threshold values for Al-stress in tree stands receiving acidic input. Our results suggest that such ratios may differ significantly between root zone and bulk soil.

The drastic difference in the effects of ectomycorrhizal and non-ectomycorrhizal exudates observed in this study underlines the important role of mycorrhizae-forming fungi for temperate and boreal forests and indicates that the use of non-mycorrhizal trees in laboratory studies may lead to erroneous results.

ACKNOWLEDGEMENTS. This research was supported by the WaBoLu-II project of the Swiss Federal Institute of Technology Zürich. We appreciate valuable comments.by James Boyle and Geri Furrer.

\section{References}

Asolekar, S.R., Valentine, R.L. and Schnoor, J.L. (1991) 'Kinetics of chemical weathering in B horizon spodosol fraction', Water Resources Res. 27, 527-532.

Akers, H.A. (1983) 'Multiple hydroxamic acid microbial iron chelators (siderophores) in soils', Soil Sci. 135, 156-159.

Baker, J.P. and Schofield, C.L. (1982) 'Aluminum toxicity to fish in acidic waters', Water Air Soil Pollut. 18, 289-309.

Boyle, J.R. and Voigt, G.K. (1973) 'Biological weathering of silicate minerals. Implications for tree nutrition and soil genesis', Plant and Soil 38, 191-201.

Brunner, I. (1992) 'Production of ectomycorrhizal Picea abies - Hebeloma crustuliniforme seedlings for ecological studies: Effects of synthesis techniques on the morphology of the symbiosis', Water Air Soil Pollut. (this issue).

Chin, P-K.F. and Mills, G.L. (1991) 'Kinetics and mechanisms of kaolinite dissolution: Effects of organic ligands', Chem. Geol. 90, 307-317.

Cronan, C.S. and Schofield, C.L. (1979) 'Aluminum leaching response to acid precipitation: Effects on high-elevation watersheds in the Northeast', Science 204, 304-306.

Cronan, C.S. and Goldstein, R.A. (1989) 'ALBIOS: A comparison of aluminum biogeochemistry in forested watersheds exposed to acidic deposition', in D.C. Adriano and M. Haves (eds), Acidic Precipitation, Vol. 1 Case Studies, Springer Verlag, New York, pp. 113-135.

Dougan, W.K. and Wilson, A.L. (1974) 'The absorptiometric determination of aluminium in water. A comparison of some chromogenic reagents and the development of an improved method', Analyst 99, 413-430.

Driscoll, C.T., Baker, J.P., Bisogni, J.J. and Schofield, C.L. (1984) 'Aluminum speciation and equilibria in dilute acidic surface waters of the Adirondack region of New York state', in O.P. Bricker (ed), Geological Aspects of Acid Precipitation, Butterworth Publishers, Boston, pp. 55-76. 
Foster, N.W. (1989) 'Acidic deposition: What is fact, what is speculation, what is needed?', Water Air Soil Pollut. 48, 299-306.

Furrer, G. and Stumm, W. (1986) 'The coordination chemistry of weathering. I. Dissolution kinetics of $\delta-\mathrm{Al}_{2} \mathrm{O}_{3}$ and BeO', Geochim. Cosmochim. Acta 50, 1847-1860.

Godo, G.H. and Reisenauer, H.M. (1980) 'Plant effects on soil manganese availabilty', Soil Sci. Soc. Am. J. 44, 993-995.

Göttlich, K. (ed) (1990) 'Moor- und Torfkunde', E. Schweizerbartsche Verlagsbuchhandlung, Stuttgart.

Huang, W.H., and Keller, W.D. (1972) 'Organic acids as agents of chemical weathering of silicate minerals', Nature 239, 149-151.

Jentschke, G., Godbold, D.L. and Hüttermann, A. (1991) 'Culture of mycorrhizal tree seedlings under controlled conditions: effects of nitrogen and aluminum', Physiol. Plant 81, 408-416.

Kodama, H., Schnitzer, M. and Jaakkimainen, M. (1983) 'Chlorite and biotite weathering by fulvic acid solutions in closed and open systems', Can. J. Soil Sci. 63, 619-629.

Kreuzer, K., Reiter, H., Schierl, R. and Göttlein, A. (1989) 'Effects of acid irrigation and liming in a Norway Spruce stand (Picea abies [L.] KARST.)', Water Air Soil Pollut. 48, 111-126.

Leyval, C. and Berthelin, J. (1991) 'Weathering of a mica by roots and rhizospheric microorganisms of pine', Soil Sci. Soc. Am. J. 55, 1009-1016.

McKeague, J.A., Cheshire, M.V., Andreux, F. and Berthelin, J. (1986) 'Organo-mineral complexes in relation to pedogenesis', in P.M. Huang and M. Schnitzer (eds), Interactions of Soil Minerals with Natural Organics and Microbes, Soil Science Society of America, Madison, pp. 549-592.

Mulder, J., van Grinsven, J.J.M., and van Breemen, N. (1987) 'Impacts of acid atmospheric deposition on woodland soils in the Netherlands: III. Aluminum chemistry', Soil Sci. Soc. Am. J. 51, 1640-1646.

Ochs, M. (1991) 'Coordinative and hydrophobic interaction of humic substances with aquatic surfaces', Ph.D. thesis, Swiss Federal Institute of Technology Zuirich.

Røyset, O. and Sullivan, T.J. (1986) 'Effect of dissolved humic compounds on the determination of aqueous aluminium by three spectrophotometric methods', Intern. J. Enviro. Anal. Chem. 27, 305-314.

Raab, D., and Stumm, W. (1992) 'Effect of acid deposition on the displacement of Al(III) in soils', Water air Soil Pollut. (this issue).

Rubio, J. and Matijevic, E. (1979) 'Interactions of metal hydroxides with chelating agents. I. $\beta$-FeOOH-EDTA', J. Colloid Interface Sci. 68, 408-421.

Schindler, P.W., Fürst, B., Dick, R. and Wolf, P.U. (1976) 'Ligand properties of surface silanol groups. I. Surface complex formation with $\mathrm{Fe}^{3+}, \mathrm{Cu}^{2+}, \mathrm{Cd}^{2+}$ and $\mathrm{Pb}^{2+}, \mathrm{J}$. Colloid Interface Sci. 55, 469-475.

Schnoor, J.L. (1990) 'Kinetics of chemical weathering: a comparison of laboratory and field weathering rates', in W. Stumm (ed), Aquatic Chemical Kinetics, John Wiley \& Sons, New York, pp. 475-504.

Schnoor, J.L., and Stumm, W. (1986) 'The role of chemical weathering in the neutralization of acidic deposition', Schweiz. Z. Hydrol. 48, 171-195.

Song, S.K. and Huang, P.M. (1988) 'Dynamics of potassium release from potassiumbearing minerals as influenced by oxalic and citric acids', Soil Sci. Soc. Am. J. 52, 383-390. 
Stumm, W. and Wieland, E. (1990) 'Dissolution of oxide and silicate minerals: Rates depend on surface speciation', in W. Stumm (ed), Aquatic Chemical Kinetics, John Wiley \& Sons, New York, pp. 367-400.

Stumm, W. and Wollast, R. (1990) 'Coordination chemistry of weathering: kinetics of the surface-controlled dissolution of oxide minerals', Reviews of Geophys. 28, 53-69.

Stumm, W., Hohl, H. and Dalang, F. (1976) 'Interaction of metal ions with hydrous oxide surfaces', Croat. Chem. Acta 48, 491-504.

Szanislo, P.J., Powell, P.E., Reid, C.P.P. and Cline, G.R. (1981) 'Production of hydroximate siderophores iron chelators by ectomychorrizal fungi', Mycologia 73, 1158-1169.

Tan, K.H. (1980) 'The release of silicon, aluminum, and potassium during decomposition of soil minerals by humic acid', Soil Sci. 129, 5-11.

Tan, K.H. (1986) 'Degradation of soil minerals by organic acids', in P.M. Huang and M. Schnitzer (eds), Interactions of Soil Minerals with Natural Organics and Microbes, Soil Science Society of America, Madison, pp. 1-28.

Ulrich, B., Mayer, R. and Khanna, P.K. (1980) 'Chemical changes due to acid precipitation in a loess-derived soil in central Europe', Soil Sci. 130, 193-199.

Valverde, N. and Wagner, C. (1976) 'Considerations on the kinetics and the mechanism of the dissolution of metal oxides in acidic solutions', Ber Bunsenges. Physik. Chem. 80, 330-333.

Wieland, E., Wehrli, B. and Stumm, W. (1988) 'The coordination chemistry of weathering: III. A generalization on the dissolution rates of minerals', Geochim. Cosmochim. Acta 52, 1969-1981.

Winkelmann, G., van der Helm, D. and Neilands, J.B. (eds) (1987) 'Iron Transport in Microbes, Plants and animals', $\mathrm{VCH}$, Weinheim. 